\title{
Endoscopic gastric atrophy is strongly associated with gastric cancer development after Helicobacter pylori eradication
}

\author{
Osamu Toyoshima ${ }^{1}$ (D) Yutaka Yamaji $^{2} \cdot$ Shuntaro Yoshida $^{1} \cdot$ Shuhei Matsumoto $^{1} \cdot$ \\ Hiroharu Yamashita $^{1,3} \cdot$ Takamitsu Kanazawa $^{1} \cdot$ Keisuke Hata $^{1,4}$
}

Received: 12 June 2016/Accepted: 23 August 2016/Published online: 7 September 2016

(C) The Author(s) 2016. This article is published with open access at Springerlink.com

\begin{abstract}
Background Risk factors for gastric cancer during continuous infection with Helicobacter pylori have been well documented; however, little has been reported on the risk factors for primary gastric cancer after $H$. pylori eradication. We conducted a retrospective, endoscopy-based, long-term, large-cohort study to clarify the risk factors for gastric cancer following $H$. pylori eradication.

Methods Patients who achieved successful H. pylori eradication and periodically underwent esophagogastroduodenoscopy surveillance thereafter at Toyoshima Endoscopy Clinic were enrolled. The primary endpoint was the development of gastric cancer. Statistical analysis was performed using the Kaplan-Meier method and Cox's proportional hazards models.

Results Gastric cancer developed in 15 of 1232 patients. The cumulative incidence rates were $1.0 \%$ at 2 years, $2.6 \%$ at 5 years, and $6.8 \%$ at 10 years. Histology showed that all gastric cancers (17 lesions) in the 15 patients were of the intestinal type, within the mucosal layer, and $<20 \mathrm{~mm}$ in diameter. Based on univariate analysis, older age and higher endoscopic grade of gastric atrophy were significantly associated with gastric cancer development
\end{abstract}

Osamu Toyoshima

t@ichou.com

1 Department of Gastroenterology, Toyoshima Endoscopy Clinic, 6-17-5 Seijo, Setagaya-ku, Tokyo 157-0066, Japan

2 Health Development Center, Tokyo Pharmaceutical Industry Health Insurance Society, Tokyo, Japan

3 Department of Gastrointestinal Surgery, Graduate School of Medicine, The University of Tokyo, Tokyo, Japan

4 Department of Surgical Oncology, Graduate School of Medicine, The University of Tokyo, Tokyo, Japan after eradication of $H$. pylori, and gastric ulcers were marginally associated. Multivariate analysis identified higher grade of gastric atrophy (hazard ratio 1.77; $95 \%$ confidence interval $1.12-2.78 ; P=0.01$ ) as the only independently associated parameter.

Conclusions Endoscopic gastric atrophy is a major risk factor for gastric cancer development after $H$. pylori eradication. Further long-term studies are required to determine whether $H$. pylori eradication leads to regression of $H$. pylori-related gastritis and reduces the risk of gastric cancer.

Keywords Stomach neoplasms - Risk factors ·

Helicobacter pylori $\cdot$ Chemoprevention · Atrophic gastritis · Endoscopy

Gastric cancer is the third leading cause of death worldwide [1], and the numbers of cases and deaths are expected to rise as the world's population increases and ages [2]. There is convincing evidence that chronic Helicobacter pylori (H. pylori) infection of the stomach provokes gastric cancer [3]. H. pylori has been estimated to be the cause of $89 \%$ of non-cardiac gastric cancers [4]. A meta-analysis of randomized controlled trials reported a reduced risk of gastric cancer following $H$. pylori eradication therapy, with a relative risk of 0.66 (95\% CI $0.46-0.95)[5,6]$.

The International Agency for Research on Cancer (IARC) Working Group Report in 2014 recommended that all countries explore the possibility of introducing population-based $H$. pylori screening and treatment programs as a strategy for gastric cancer prevention [2]. In Japan, national health insurance coverage was approved for eradication therapy in patients with endoscopically diagnosed chronic gastritis caused by $H$. pylori infection in February $2013[2,7]$. 
Gastric cancer can develop even after eradication of $H$. pylori. If nationwide $H$. pylori treatment is conducted, then the majority of new gastric cancer cases will develop from "inactive" gastritis after $H$. pylori eradication. Identifying the characteristics and risk factors, other than active $H$. pylori infection, for gastric cancer that are not prevented by $H$. pylori eradication is thus key to designing strategies for controlling gastric cancer. The risk factors for gastric cancer during continuous infection with $H$. pylori have been well documented [2, 8-12], and several reports of metachronous gastric cancers after eradication in patients with endoscopically resected gastric cancer have been published [13-16]. However, little has been reported on the risk factors for primary gastric cancer after $H$. pylori eradication [17-19], especially in a large population of patients with plain chronic gastritis without peptic ulcers.

This study aimed to investigate the risk factors associated with primary gastric cancer after eradication of $H$. pylori. We conducted a retrospective, endoscopy-based, long-term cohort study involving a large cohort of patients with chronic gastritis without peptic ulcers and evaluated associations of various parameters with the risk of gastric cancer using multivariate analyses.

\section{Materials and Methods}

\section{Patients}

Patients who underwent esophagogastroduodenoscopy (EGD) at Toyoshima Endoscopy Clinic in Tokyo, Japan, between April 2002 and June 2014, were diagnosed with $H$. pylori infection, and achieved successful $H$. pylori eradication were included. These patients underwent EGD either for screening, a previous history of esophagogastroduodenal disease, present symptoms, abnormal findings by barium meal, or an abnormal serum pepsinogen level. Patients diagnosed as having gastric neoplasia (category 3,4 , or 5 according to the Vienna classification; i.e., noninvasive low-grade neoplasia, noninvasive high-grade neoplasia, or invasive neoplasia) [20] based on EGD at the time of enrollment were excluded. When lesions suspected to be gastric neoplasia were found but not determined histologically by EGD at the time of enrollment, the patients with those lesions were excluded if gastric neoplasia were confirmed within 1 year after $H$. pylori eradication. The other exclusion criteria were a past history of gastric neoplasia, previous gastrectomy, age younger than 20 years, or severe concomitant illness. Informed consent for each EGD and $H$. pylori eradication therapy was obtained from all patients.

The ethics review committees of external organizations approved the study protocol.
Endoscopic findings and diagnosis of gastric cancer

EGD was performed by certificated endoscopists at Toyoshima Endoscopy Clinic using videoscopes (GIFH240, GIF-H260, or GIF-HQ290, Olympus, Tokyo, Japan). Biopsy specimens were taken from lesions suspected to be gastric cancer or other major gastric findings and assessed histologically.

Histological evaluation was conducted according to the Vienna classification [20]. Gastric neoplasia was defined as category 3,4 , or 5 according to the Vienna classification (i.e., noninvasive low-grade neoplasia, noninvasive highgrade neoplasia, or invasive neoplasia). The diagnosis of gastric cancer was confirmed histologically using specimens from en bloc resection by endoscopy or surgery. Gastric cancer was defined as category 4 or 5 according to the Vienna classification (i.e., noninvasive high-grade neoplasia or invasive neoplasia). Lesions diagnosed as category 4 or 5 by biopsy were resected by endoscopy or surgery. Patients with category 3 lesions were recommended to undergo resection for precise diagnosis and to prevent progression to cancer. Based on the patient's decision, the lesion was resected or followed up annually. Gastric cancer was classified according to Lauren as either the intestinal or diffuse type [21]. Patients with gastric or duodenal ulcer scars were also classified as having gastric or duodenal ulcers.

\section{Grade of gastric atrophy}

Gastric mucosal atrophy was evaluated according to the endoscopic-atrophic-border scale described by Kimura and Takemoto [22], which correlates with the results of histological evaluation [23]. They endoscopically categorized gastric atrophy as closed or open, where closed denoted mild and open denoted advanced atrophy. The endoscopicatrophic-border was recognized as an almost symmetrical enclosure in the closed type, but not the open type. Each type of atrophy was also graded, where Grade 0 described no visible atrophy, Grade 1 (C-I) closed atrophy limited to the antrum, Grade 2 (C-II) closed atrophy limited to the antrum and lesser curvature of the distal gastric body, Grade 3 (C-III) closed atrophy including the antrum and lesser curvature of the proximal gastric body, Grade 4 (O-I) open atrophy with the atrophic border lying between the lesser curvature and the anterior wall, Grade 5 (O-II) open atrophy with the atrophic border lying amid the anterior wall, and Grade 6 (O-III) open atrophy widely spread with the border between the anterior wall and the greater curvature. Typical endoscopic images are shown in Figs. 1, 2, and 3. 
Fig. 1 A A case of closed-type atrophy, Grade 3 (C-III): closed atrophy with the atrophic border recognized as an almost symmetrical enclosure and including the antrum and lesser curvature of the proximal gastric body. B The endoscopicatrophic-border is indicated by a dotted line
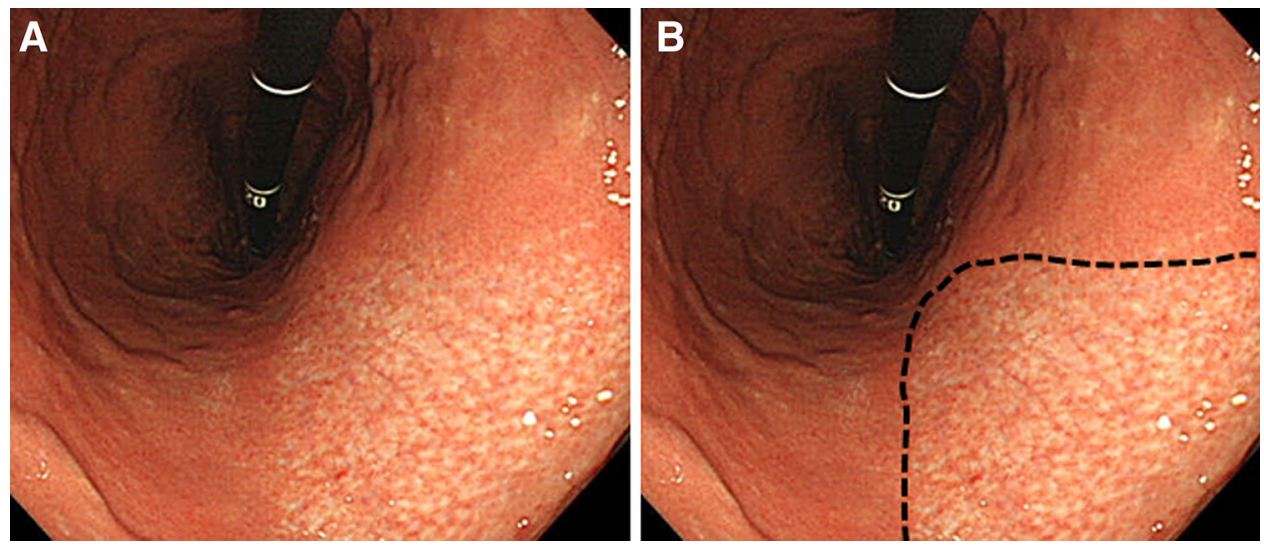

Fig. 2 A A case of mild opentype atrophy, Grade 5 (O-II): open atrophy with the atrophic border lying amid the anterior wall. B The endoscopicatrophic-border is indicated by a dotted line
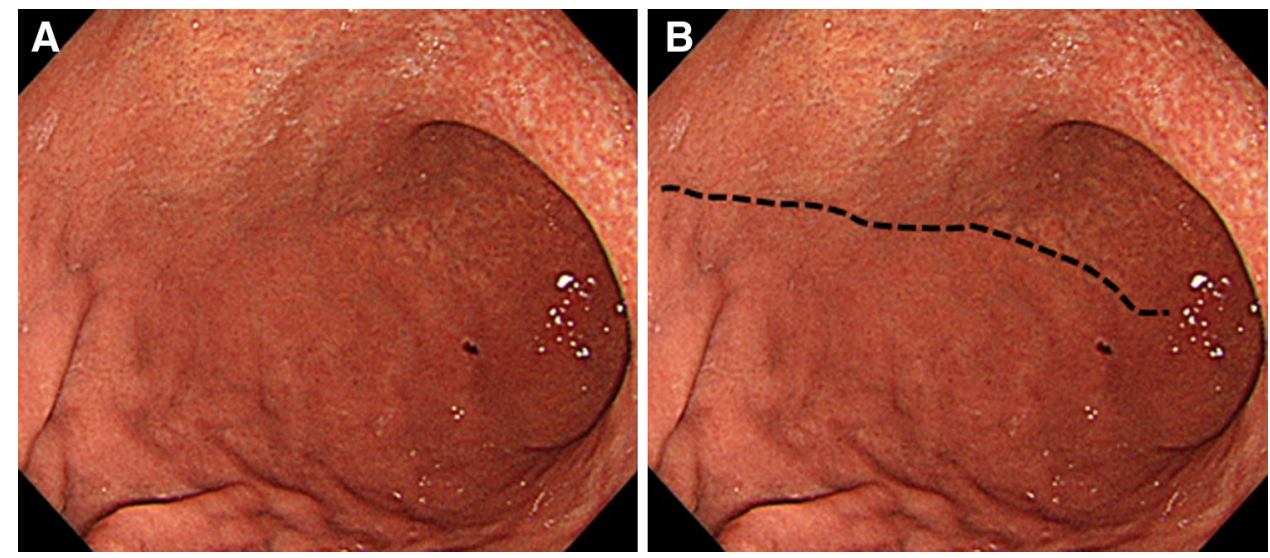

Fig. 3 A A case of severe open-type atrophy, Grade 6 (OIII): open atrophy widely spread with the border between the anterior wall and the greater curvature. B The obscure endoscopic-atrophic-border is indicated by a dotted line
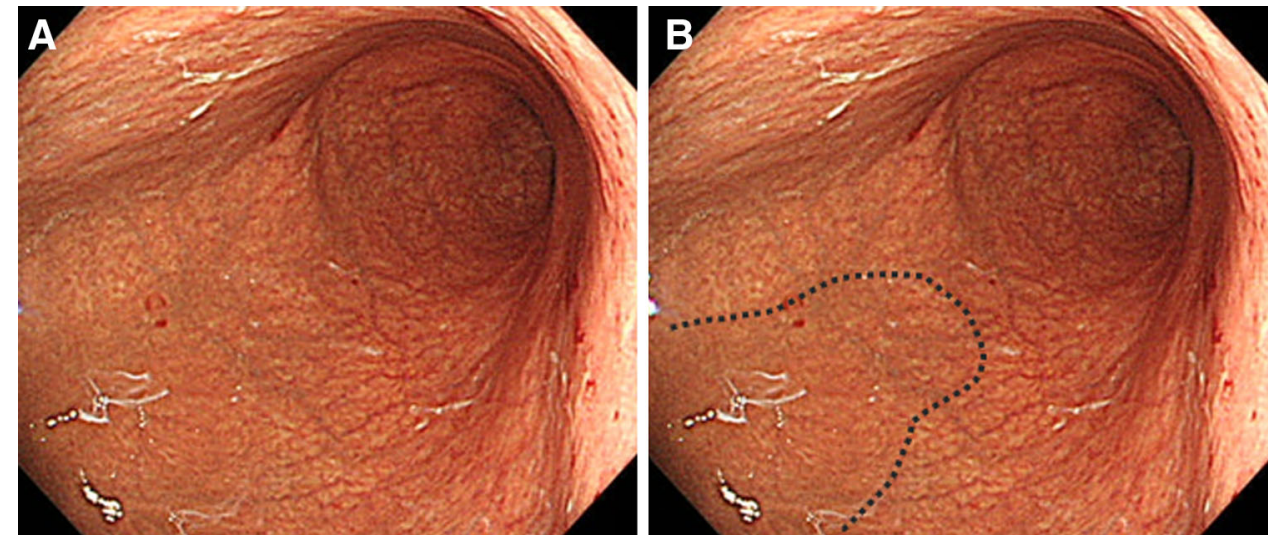

\section{Diagnosis and treatment of $H$. pylori infection}

H. pylori infection was diagnosed based on one or more positive results of the following $H$. pylori tests: ${ }^{13} \mathrm{C}$-urea breath test, serum anti-H. pylori antibody, $H$. pylori antigen in feces, or histology (hematoxylin and eosin, Giemsa, or immunologic staining).

All patients were informed of their infection status, and those with active $H$. pylori infection who consented to the eradication therapy received the following treatment regimens: lansoprazole $(30 \mathrm{mg})$ or rabeprazole sodium $(10 \mathrm{mg})$ together with amoxicillin $(750 \mathrm{mg})$ and clarithromycin (200 or $400 \mathrm{mg}$ ) or metronidazole $(250 \mathrm{mg}$ ) twice daily for 1 week. Participants in whom eradication treatment failed or who were allergic to penicillin were invited to undergo a second-line regimen: lansoprazole $(30 \mathrm{mg})$ or rabeprazole sodium $(10 \mathrm{mg})$ twice daily and a combination of amoxicillin $(750 \mathrm{mg})$ and sitafloxacin $(100 \mathrm{mg})$, or metronidazole $(250 \mathrm{mg})$ and minomycin $(100 \mathrm{mg}$ ) twice daily for 1 week, or amoxicillin $(750 \mathrm{mg})$ twice and levofloxacin $(500 \mathrm{mg})$ once daily for 10 days. 
At least 8 weeks after the completion of eradication therapy, successful eradication was confirmed using one or two of the following measurements: negative ${ }^{13} \mathrm{C}$-urea breath test at two weeks after cessation of maintenance therapy with acid suppressors or negative $H$. pylori antigen in feces.

\section{Outcome measurement}

We performed annual EGD surveillance after eradication of $H$. pylori infection for early detection of gastric cancer. The primary endpoint was the development of gastric cancer, and data were censored at the date of the final EGD. The effects of the following factors on gastric cancer development after $H$. pylori eradication were evaluated: sex, age, family history of gastric cancer, body mass index, drinking (every day or less), smoking (current or not), gastric ulcer, duodenal ulcer, and grade of gastric atrophy.

\section{Statistical analysis}

Cumulative incidence rates of gastric cancer development were estimated using the Kaplan-Meier method. KaplanMeier curves were compared between gastric atrophy groups by the log-rank test. Hazard ratios (HRs) with $95 \%$ CIs were calculated using Cox's proportional hazards models in univariate and multivariate analyses. A multivariate analysis was performed for factors with $P$ values $<0.1$ in univariate analyses. All statistical analyses were performed using IBM SPSS version 21.0 (IBM SPSS, Armonk, NY). All $P$ values were two-sided; significance was indicated by a $P$ value of less than 0.05 .

\section{Results}

Of the 1270 patients that fulfilled our inclusion criteria, 8 with gastric cancer (category 5: five patients, category 4 : three) at the time of enrollment were excluded. In addition, four patients with lesions suspicious for gastric neoplasms were excluded because these lesions were confirmed to be gastric cancer (category 5: three, category 4: one) within 1 year after $H$. pylori eradication. Nineteen patients were excluded because they had a past history of gastric neoplasm (18 with category 4 or 5 , one with category 3 ), 6 patients because they had undergone gastrectomy for peptic ulcer, and one patient because he was under 20 years old. Consequently, in total 1232 patients were analyzed.

The demographic characteristics of eligible patients are shown in Table 1. The mean age was 54.1 years; 661 patients were female; and 571 were male. Of them, 208 had gastric ulcer, 229 had duodenal ulcers, 53 had both gastric and duodenal ulcers, and 848 had only gastritis. Five hundred and seventy-eight patients had closed-type atrophy (Grade 0: 38, Grade 1: 68, Grade 2: 311, and Grade 3: 161) and 654 had open-type atrophy (Grade 4: 216, Grade 5: 162, and Grade 6: 276).

During the follow-up period, gastric cancer developed in 15 of 1232 patients after eradication of $H$. pylori infection (mean follow-up duration 2.46 years). The cumulative incidence rates of gastric cancer were $1.0 \%$ at 2 years, $2.6 \%$ at 5 years, and $6.8 \%$ at 10 years (Fig. 4). All gastric cancers (17 lesions) that developed in the 15 patients were of the intestinal type based on Lauren's classification, within the mucosal layer, and $<20 \mathrm{~mm}$ in diameter. Endoscopic images of a typical case of gastric cancer are shown in Fig. 5.

Among the 17 lesions, nine were classified as category 5 and eight as category 4. One patient had two lesions of category 5 , and another patient had one category 5 and one category 4 lesion simultaneously. There were some discrepancies in category between biopsy specimens and those obtained by en bloc resection. Five lesions classified as category 4 by biopsy analysis were diagnosed as category 5 following resection, and three determined to be category 3 by biopsy were corrected to category 4 . Two patients with lesions diagnosed as category 3 by biopsy did not agree to undergo resection. These patients were followed up by annual EGD; one lesion retained a diagnosis of category 3 and the other became undetectable, though it may be resectable by repeated cold biopsies. These two cases were categorized into the no cancer development group, and data were censored at the time of the final EGDs.

By univariate analysis using Cox's proportional hazards model, older age $(P=0.006)$ and higher grade of gastric atrophy $(P=0.002)$ were significantly associated, and gastric ulcer $(P=0.09)$ was marginally associated, with gastric cancer development after eradication of $H$. pylori infection (Table 2). A multivariate analysis was performed incorporating the parameters with $P$ values $<0.1$ in the univariate analysis. This identified higher grade of gastric atrophy (HR 1.77; $95 \%$ CI $1.12-2.78 ; P=0.01$ ) as the only parameter independently associated with development of gastric cancer after eradication (Table 3).

The cumulative incidence rates of gastric cancer in closed-type atrophy (Grade 0-3), mild open-type atrophy (Grade 4 or $5 ; P=0.02$ vs. closed-type atrophy), and severe open-type atrophy (Grade $6 ; P=0.0002$ vs. closedtype atrophy) are shown in Fig. 6.

\section{Discussion}

In this study, a higher grade of gastric atrophy was the only parameter independently associated with gastric cancer development after eradication of $H$. pylori. Although older 
Table 1 Demographic characteristics of patients

\begin{tabular}{|c|c|c|c|c|c|}
\hline \multicolumn{2}{|l|}{ Characteristics } & \multirow{2}{*}{$\begin{array}{l}\text { All patients } \\
(N=1232)\end{array}$} & \multirow{2}{*}{$\begin{array}{l}\text { Gastric cancer development } \\
(N=15) \\
7 / 8\end{array}$} & \multirow{2}{*}{$\begin{array}{l}\text { No gastric cancer development } \\
(N=1217) \\
654 / 563\end{array}$} & \multirow{2}{*}{$\frac{p \text { value }^{\mathrm{a}}}{0.59}$} \\
\hline Sex & Female/male & & & & \\
\hline Age & & $54.1 \pm 13$ & $65.1 \pm 8.5$ & $54.0 \pm 13.0$ & 0.0009 \\
\hline $\begin{array}{l}\text { Family history of gastric } \\
\text { cancer }\end{array}$ & Yes/no & $211 / 1021$ & $5 / 10$ & $206 / 1011$ & 0.16 \\
\hline Body mass index & & $22.1 \pm 3.1$ & $23.1 \pm 3.2$ & $22.1 \pm 3.1$ & 0.2 \\
\hline Drinking & Yes/no & $626 / 606$ & $8 / 7$ & $618 / 599$ & 0.84 \\
\hline Smoking & Yes/no & $353 / 879$ & $1 / 14$ & $352 / 865$ & 0.08 \\
\hline Gastric ulcer & Yes/no & $208 / 1024$ & $5 / 10$ & $203 / 1014$ & 0.15 \\
\hline Duodenal ulcer & Yes/no & $229 / 1003$ & $1 / 14$ & $228 / 989$ & 0.33 \\
\hline \multirow[t]{7}{*}{ Grade of gastric atrophy } & 0 & 38 & 0 & 38 & \multirow[t]{7}{*}{0.0003} \\
\hline & 1 & 68 & 0 & 68 & \\
\hline & 2 & 311 & 0 & 311 & \\
\hline & 3 & 161 & 1 & 160 & \\
\hline & 4 & 216 & 3 & 213 & \\
\hline & 5 & 162 & 2 & 160 & \\
\hline & 6 & 276 & 9 & 267 & \\
\hline
\end{tabular}

Bold values indicate statistical significance $(p<0.05)$

${ }^{a} p$ values derived from the Chi-squared tests, Student $t$ tests, Fisher's exact tests, and Mann-Whitney $U$ tests as appropriate

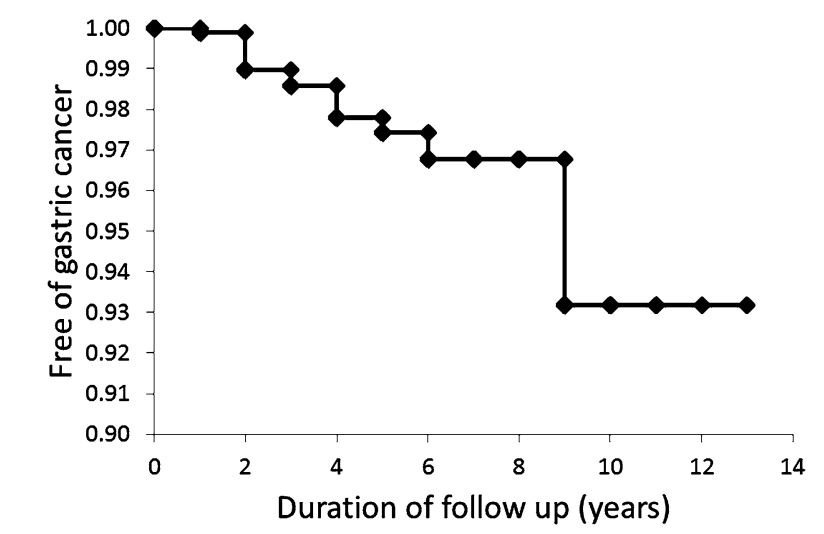

$\begin{array}{llllllll}\text { No. at Risk } & 1232 & 657 & 377 & 146 & 38 & 10 & 2\end{array}$

Fig. 4 Kaplan-Meier analysis of the proportion of patients who remained free of gastric cancer

age and gastric ulcer were associated in univariate analyses (older age significantly and ulcer marginally), they were not significant in the multivariate analysis.

Several studies have reported on patients with endoscopically resected gastric cancer, and two regarded gastric atrophy to be a risk factor for metachronous gastric cancer even after $H$. pylori eradication $[13,14]$. On the other hand, reports on the risk factors for primary gastric cancer after H. pylori eradication, especially in a large population of plain chronic gastritis patients without peptic ulcers, are limited. Kamada et al. [17] reported in their cohort study of 1787 patients, including 453 with plain atrophic gastritis, that all patients in whom gastric cancer developed after $H$. pylori eradication had severe histological atrophy in the corpus. Take et al. [18] reported in their cohort study of patients with peptic ulcer diseases that persistent $H$. pylori infection, advanced gastric mucosal atrophy, and old age were significant risk factors for gastric cancer development after H. pylori eradication therapy. Kodama et al. [19] reported in their case-control study that patients who developed gastric cancer had a higher level of gastric atrophy and intestinal metaplasia than those who did not. In patients with continuous $H$. pylori infection, several risk factors have been identified as important parameters, including gastric atrophy. Age, gastric atrophy, intestinal metaplasia, gastric ulcer, absence of duodenal ulcer, drinking, and smoking habits have also been investigated [8-12]. Although multiple factors were assessed in the present study, only gastric atrophy was independently associated with gastric cancer development. One of the main reasons may lie in the fact that eradication of $H$. pylori incompletely and heterogeneously reverses the changes induced by chronic $H$. pylori infection. Histological inflammation improves or even normalizes in a few months, while atrophy gradually improves in a few years; intestinal metaplasia has also been reported to improve in 10 years [12, 24-26]. H. pylori eradication leads to normalization of gastric acid secretion in patients without severe atrophy [27], and improvement of expression of sonic hedgehog and CDX2 in mucosa with incomplete intestinal metaplasia [28], but MLH1 methylation is not 

typical case of gastric cancer.

A White-light imaging.

B White-light imaging with

indigo carmine dye application
Fig. 5 Endoscopic images of a
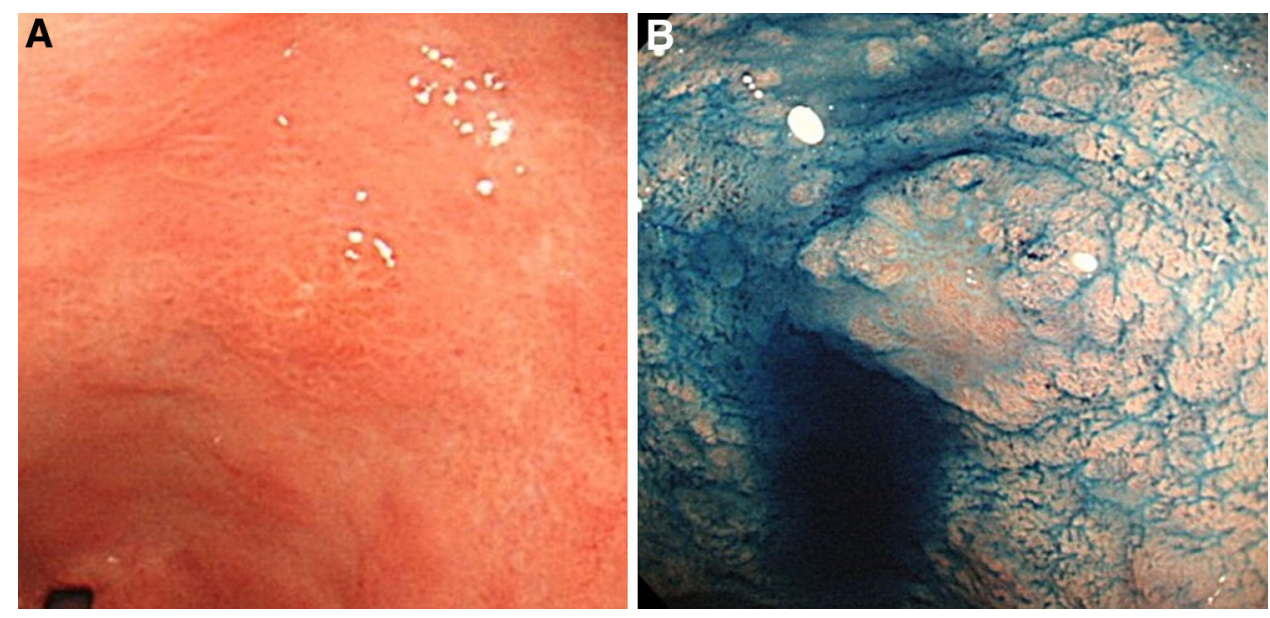

Table 2 Univariate analysis of factors associated with gastric cancer development after eradication of $H$. pylori infection (Cox's proportional hazards model)

\begin{tabular}{llll}
\hline Factors & & Hazard ratio & $p$ value \\
\hline Sex & Male & 1.23 & 0.68 \\
Age & Per 1 year & $\mathbf{1 . 0 7}$ & $\mathbf{0 . 0 0 6}$ \\
Family history of gastric cancer & Yes & 1.90 & 0.24 \\
Body mass index & Per 1 kg/m² & 1.09 & 0.28 \\
Drinking & Yes & 1.02 & 0.96 \\
Smoking & Yes & 0.22 & 0.15 \\
Gastric ulcer & Yes & 2.53 & 0.09 \\
Duodenal ulcer & Yes & 0.34 & 0.29 \\
Grade of gastric atrophy & Per 1 rank & $\mathbf{1 . 9 7}$ & $\mathbf{0 . 0 0 2}$ \\
\hline
\end{tabular}

Bold values indicate statistical significance $(p<0.05)$

Table 3 Multivariate analysis of factors associated with gastric cancer development after eradication of $H$. pylori infection (Cox's proportional hazards model)

\begin{tabular}{lllll}
\hline Factors & & Hazard ratio & $95 \%$ CI & $p$ value \\
\hline Age & Per 1 year & 1.05 & $0.99-1.10$ & 0.10 \\
Gastric ulcer & Yes & 2.43 & $0.82-7.26$ & 0.11 \\
Grade of gastric atrophy & Per 1 rank & $\mathbf{1 . 7 7}$ & $1.12-2.78$ & $\mathbf{0 . 0 1}$ \\
\hline
\end{tabular}

Bold values indicate statistical significance $(p<0.05)$

CI confidence interval

affected in patients with intestinal metaplasia [29]. Wong et al. [9] and Yanaoka et al. [30] suggested that the effect of $H$. pylori eradication on reducing gastric cancer development would be greater for patients at an earlier stage of the gastric cancer cascade than those in later phases with advanced gastric atrophy or metaplasia. Therefore, gastric atrophy may be an important risk factor for gastric cancer development after eradication of $H$. pylori infection.

Intestinal-type gastric cancer develops mainly through the atrophy-metaplasia-dysplasia-cancer sequence [31]. On the other hand, inflammation induced by $H$. pylori can directly generate diffuse-type cancer from the non-atrophic stomach [32]. After H. pylori eradication, histological inflammation improves, rugal hyperplasia markedly regresses, and diffuse-type cancer development appears to be suppressed, according to a study by Watanabe et al. [33]. Indeed, in the present study, all 17 cancers in the 15 patients were of intestinal type. Diffuse-type cancer may be prevented within a short period after eradication of $H$. pylori, while the intestinal type continues to develop at a considerable rate for more than 10 years after eradication. The latter might start to regress when gastric atrophy and intestinal metaplasia begin to improve after a considerable period of time.

Generally, gastric cancer after eradication of H. pylori infection could include lesions missed at the time of 


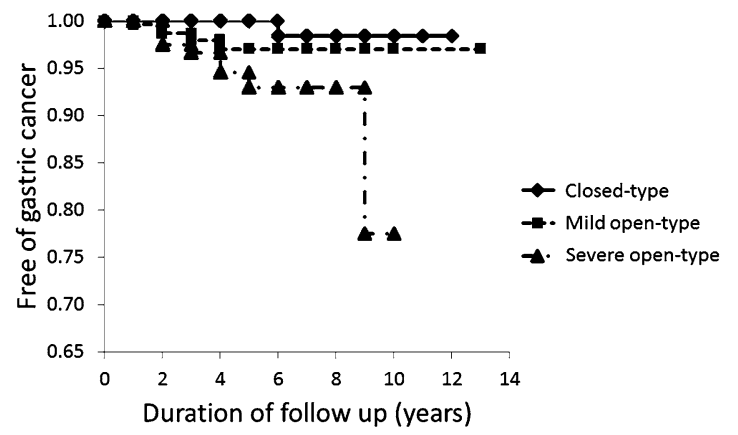

No. at Risk

$\begin{array}{llllllll}\text { Closed-type } & 578 & 297 & 185 & 66 & 18 & 6 & 1\end{array}$

$\begin{array}{llllllll}\text { Mild open-type } & 378 & 205 & 101 & 40 & 9 & 2 & 1\end{array}$

$\begin{array}{llllllll}\text { Severe open-type } & 276 & 156 & 91 & 41 & 11 & 2 & 0\end{array}$

Fig. 6 Kaplan-Meier analysis of the proportion of patients who remained free of gastric cancer stratified by the grade of gastric mucosal atrophy

eradication. In this study, we enrolled only patients in whom absence of neoplasm was confirmed by endoscopy. We also excluded patients with indeterminate lesions that were suspected to be gastric neoplasia and later confirmed as gastric cancer within 1 year after $H$. pylori eradication. The annual incidence rate of gastric cancer in this study averaged $0.5 \%$ per year during the first 5 years, while the rate in the first year was $0.1 \%$ per year, and the cumulative incidence rate was $1.0 \%$ at 2 years. Several reports have suggested that $H$. pylori eradication might induce a flattened or dimmed appearance of some small gastric cancer lesions [34]. Therefore, some lesions may be difficult to detect after 1 year. Gastric cancers found in our cohort were all within the mucosal layer and $<20 \mathrm{~mm}$ in diameter, suggesting that they were identified at an early stage. We attempted to conduct endoscopy as precisely as possible by routinely using sufficient sedation, contrasting the mucosa by dyeing with indigo carmine, and vigorously taking biopsies from small and depressed lesions, which have been reported to be characteristics of cancer after $H$. pylori eradication [17, 35]. The incidence rates of gastric cancer in the present study were higher than those in previous studies involving patients of similar age and $H$. pylori status [8-10, 17, 18, 30]. Our method of vigorous biopsies accompanied by dyeing might enable detection of smaller and more obscure lesions at an early stage.

There were several limitations to this study. First, the number of patients was too small for multiple factors to be evaluated fully. However, gastric mucosal atrophy identified by endoscopy was significantly associated with gastric cancer development after eradication of $H$. pylori infection. Second, we could not assess intestinal metaplasia. Histological intestinal metaplasia could also predict gastric cancer development $[8,36]$. We did not routinely conduct biopsies of the background gastric mucosa in each patient.
Given that progression of gastritis was the major risk factor for gastric cancer development even after eradication of $H$. pylori, the optimal indicator to evaluate gastritis should be determined. In particular, pathological indicators are likely to be informative and should be investigated in future studies. Third, Cag A status was not assessed. Because most $H$. pylori isolates from East Asia express the Cag A gene, our results indicate mainly the risk of infection with Cag A-positive species [2,3]. Further analyses of other bacterial factors together with host genetic and environmental factors that modulate the response to $H$. pylori infection are warranted. Fourth, because ten endoscopists were engaged in this study, there might have been some variations in evaluations among the endoscopists. However, since all endoscopists were certified by the Japan Gastroenterological Endoscopy Society and familiar with endoscopic classification, endoscopies performed in the same patients were assumed to be generally congruent.

In conclusion, endoscopic gastric atrophy is a major risk factor for gastric cancer development after $H$. pylori eradication. Patients with advanced atrophy should be carefully monitored for at least 10 years. Further long-term studies are required to determine whether $H$. pylori eradication leads to regression of $H$. pylori-related gastritis and a reduced risk of gastric cancer.

\section{Compliance with ethical standards}

Disclosures Drs. Osamu Toyoshima, Yutaka Yamaji, Shuntaro Yoshida, Shuhei Matsumoto, Hiroharu Yamashita, Takamitsu Kanazawa, and Keisuke Hata have no conflicts of interest or financial ties to disclose.

Open Access This article is distributed under the terms of the Creative Commons Attribution 4.0 International License (http://crea tivecommons.org/licenses/by/4.0/), which permits unrestricted use, distribution, and reproduction in any medium, provided you give appropriate credit to the original author(s) and the source, provide a link to the Creative Commons license, and indicate if changes were made.

\section{References}

1. International Agency for Research on Cancer. Stomach cancer. Estimated incidence, mortality and prevalence worldwide in 2012. [Cited 2016 12/6]. http://globocan.iarc.fr/Pages/fact_ sheets_cancer.aspx

2. International Agency for Research on Cancer. Helicobacter pylori eradication as a strategy for preventing gastric cancer. IARC working group reports, vol 8. [Cited 2016 12/6]. http:// www.iarc.fr/en/publications/pdfs-online/wrk/wrk8/Helicobacter_ pylori_Eradication.pdf

3. International Agency for Research on Cancer. Helicobacter pylori. Biological agents, volume $100 \mathrm{~B}$. A review of human carcinogens, pp 385-435. [Cited 2016 12/6]. http://monographs. iarc.fr/ENG/Monographs/vol100B/mono100B.pdf 
4. Plummer M, Franceschi S, Vignat J, Forman D, de Martel C (2015) Global burden of gastric cancer attributable to Helicobacter pylori. Int J Cancer 136:487-490

5. Ma JL, Zhang L, Brown LM, Li JY, Shen L, Pan KF, Liu WD, Hu Y, Han ZX, Crystal-Mansour S, Pee D, Blot WJ, Fraumeni JF Jr, You WC, Gail MH (2012) Fifteen-year effects of Helicobacter pylori, garlic, and vitamin treatments on gastric cancer incidence and mortality. J Natl Cancer Inst 104:488-492

6. Ford AC, Forman D, Hunt RH, Yuan Y, Moayyedi P (2014) Helicobacter pylori eradication therapy to prevent gastric cancer in healthy asymptomatic infected individuals: systematic review and meta-analysis of randomised controlled trials. BMJ 348:g3174

7. Asaka M, Kato M, Sakamoto N (2014) Roadmap to eliminate gastric cancer with Helicobacter pylori eradication and consecutive surveillance in Japan. J Gastroenterol 49:1-8

8. Uemura N, Okamoto S, Yamamoto S, Matsumura N, Yamaguchi S, Yamakido M, Taniyama K, Sasaki N, Schlemper RJ (2001) Helicobacter pylori infection and the development of gastric cancer. N Engl J Med 345:784-789

9. Wong BC, Lam SK, Wong WM, Chen JS, Zheng TT, Feng RE, Lai KC, Hu WH, Yuen ST, Leung SY, Fong DY, Ho J, Ching CK, Chen JS (2004) Helicobacter pylori eradication to prevent gastric cancer in a high-risk region of China: a randomized controlled trial. JAMA 291:187-194

10. Yamaji Y, Watabe H, Yoshida H, Kawabe T, Wada R, Mitsushima T, Omata M (2009) High-risk population for gastric cancer development based on serum pepsinogen status and lifestyle factors. Helicobacter 14:81-86

11. Tanikawa C, Urabe Y, Matsuo K, Kubo M, Takahashi A, Ito H, Tajima K, Kamatani N, Nakamura Y, Matsuda K (2012) A genome-wide association study identifies two susceptibility loci for duodenal ulcer in the Japanese population. Nat Genet 44:430-434

12. Dinis-Ribeiro M, Areia M, de Vries AC, Marcos-Pinto R, Monteiro-Soares M, O'Connor A, Pereira C, Pimentel-Nunes P, Correia R, Ensari A, Dumonceau JM, Machado JC, Macedo G, Malfertheiner P, Matysiak-Budnik T, Megraud F, Miki K, O'Morain C, Peek RM, Ponchon T, Ristimaki A, Rembacken B, Carneiro F, Kuipers EJ (2012) Management of precancerous conditions and lesions in the stomach (MAPS): guideline from the European Society of Gastrointestinal Endoscopy (ESGE), European Helicobacter Study Group (EHSG), European Society of Pathology (ESP), and the Sociedade Portuguesa de Endoscopia Digestiva (SPED). Endoscopy 44:74-94

13. Hanaoka N, Uedo N, Shiotani A, Inoue T, Takeuchi Y, Higashino K, Ishihara R, Iishi H, Haruma K, Tatsuta M (2010) Autofluorescence imaging for predicting development of metachronous gastric cancer after Helicobacter pylori eradication. J Gastroenterol Hepatol 25:1844-1849

14. Maehata Y, Nakamura S, Fujisawa K, Esaki M, Moriyama T, Asano K, Fuyuno Y, Yamaguchi K, Egashira I, Kim H, Kanda M, Hirahashi M, Matsumoto T (2012) Long-term effect of Helicobacter pylori eradication on the development of metachronous gastric cancer after endoscopic resection of early gastric cancer. Gastrointest Endosc 75:39-46

15. Watari J, Moriichi K, Tanabe H, Kashima S, Nomura Y, Fujiya M, Tomita T, Oshima T, Fukui H, Miwa H, Das KM, Kohgo Y (2012) Biomarkers predicting development of metachronous gastric cancer after endoscopic resection: an analysis of molecular pathology of Helicobacter pylori eradication. Int J Cancer 130:2349-2358

16. Sugimoto T, Yamaji Y, Sakitani K, Isomura Y, Yoshida S, Yamada A, Hirata Y, Ogura K, Okamoto M, Koike K (2015) Neutrophil infiltration and the distribution of intestinal metaplasia is associated with metachronous gastric cancer following endoscopic submucosal dissection. Can J Gastroenterol Hepatol 29:321-325

17. Kamada T, Hata J, Sugiu K, Kusunoki H, Ito M, Tanaka S, Inoue K, Kawamura Y, Chayama K, Haruma K (2005) Clinical features of gastric cancer discovered after successful eradication of Helicobacter pylori: results from a 9-year prospective follow-up study in Japan. Aliment Pharmacol Ther 21:1121-1126

18. Take S, Mizuno M, Ishiki K, Nagahara Y, Yoshida T, Yokota K, Oguma K (2007) Baseline gastric mucosal atrophy is a risk factor associated with the development of gastric cancer after Helicobacter pylori eradication therapy in patients with peptic ulcer diseases. J Gastroenterol 42(Suppl 17):21-27

19. Kodama M, Murakami K, Okimoto T, Abe H, Sato R, Ogawa R, Mizukami K, Shiota S, Nakagawa Y, Soma W, Arita T, Fujioka T (2013) Histological characteristics of gastric mucosa prior to Helicobacter pylori eradication may predict gastric cancer. Scand J Gastroenterol 48:1249-1256

20. Schlemper R, Riddell R, Kato Y, Borchard F, Cooper H, Dawsey S, Dixon M, Fenoglio-Preiser C, Flejou J, Geboes K, Hattori T, Hirota T, Itabashi M, Iwafuchi M, Iwashita A, Kim Y, Kirchner T, Klimpfinger M, Koike M, Lauwers G, Lewin K, Oberhuber G, Offner F, Price A, Rubio C, Shimizu M, Shimoda T, Sipponen P, Solcia E, Stolte M, Watanabe H, Yamabe H (2000) The Vienna classification of gastrointestinal epithelial neoplasia. Gut 47:251-255

21. Lauren P (1965) The two histological main types of gastric carcinoma: diffuse and so-called intestinal-type carcinoma. An attempt at a histo-clinical classification. Acta Pathol Microbiol Scand 64:31-49

22. Kimura K, Takemoto T (1969) An endoscopic recognition of the atrophic border and its significance in chronic gastritis. Endoscopy 3:87-97

23. Satoh K, Kimura K, Taniguchi Y, Yoshida Y, Kihira K, Takimoto T, Kawata H, Saifuku K, Ido K, Takemoto T, Ota Y, Tada M, Karita M, Sakaki N, Hoshihara Y (1996) Distribution of inflammation and atrophy in the stomach of Helicobacter pyloripositive and -negative patients with chronic gastritis. Am J Gastroenterol 91:963-969

24. Ohkusa T, Fujiki K, Takashimizu I, Kumagai J, Tanizawa T, Eishi Y, Yokoyama T, Watanabe M (2001) Improvement in atrophic gastritis and intestinal metaplasia in patients in whom Helicobacter pylori was eradicated. Ann Intern Med 134:380-386

25. Mera R, Fontham ET, Bravo LE, Bravo JC, Piazuelo MB, Camargo MC, Correa P (2005) Long term follow up of patients treated for Helicobacter pylori infection. Gut 54:1536-1540

26. Kodama M, Murakami K, Okimoto T, Sato R, Uchida M, Abe T, Shiota S, Nakagawa Y, Mizukami K, Fujioka T (2012) Ten-year prospective follow-up of histological changes at five points on the gastric mucosa as recommended by the updated Sydney system after Helicobacter pylori eradication. J Gastroenterol 47:394-403

27. Iijima K, Sekine H, Koike T, Imatani A, Ohara S, Shimosegawa $\mathrm{T}$ (2004) Long-term effect of Helicobacter pylori eradication on the reversibility of acid secretion in profound hypochlorhydria. Aliment Pharmacol Ther 19:1181-1188

28. Shiotani A, Uedo N, Iishi H, Tatsuta M, Ishiguro S, Nakae Y, Kamada T, Haruma K, Merchant JL (2007) Re-expression of sonic hedgehog and reduction of CDX2 after Helicobacter pylori eradication prior to incomplete intestinal metaplasia. Int J Cancer 121:1182-1189

29. Perri F, Cotugno R, Piepoli A, Merla A, Quitadamo M, Gentile A, Pilotto A, Annese V, Andriulli A (2007) Aberrant DNA methylation in non-neoplastic gastric mucosa of $H$. pylori infected patients and effect of eradication. Am $\mathbf{J}$ Gastroenterol 102:1361-1371 
30. Yanaoka K, Oka M, Ohata H, Yoshimura N, Deguchi H, Mukoubayashi C, Enomoto S, Inoue I, Iguchi M, Maekita T, Ueda K, Utsunomiya H, Tamai H, Fujishiro M, Iwane M, Takeshita T, Mohara O, Ichinose M (2009) Eradication of Helicobacter pylori prevents cancer development in subjects with mild gastric atrophy identified by serum pepsinogen levels. Int $\mathrm{J}$ Cancer 125:2697-2703

31. Correa P, Houghton J (2007) Carcinogenesis of Helicobacter pylori. Gastroenterology 133:659-672

32. Nardone G, Rocco A, Malfertheiner P (2004) Review article: Helicobacter pylori and molecular events in precancerous gastric lesions. Aliment Pharmacol Ther 20:261-270

33. Watanabe M, Kato J, Inoue I, Yoshimura N, Yoshida T, Mukoubayashi C, Deguchi H, Enomoto S, Ueda K, Maekita T, Iguchi M, Tamai H, Utsunomiya H, Yamamichi N, Fujishiro M, Iwane M, Tekeshita T, Mohara O, Ushijima T, Ichinose M (2012) Development of gastric cancer in nonatrophic stomach with highly active inflammation identified by serum levels of pepsinogen and Helicobacter pylori antibody together with endoscopic rugal hyperplastic gastritis. Int $\mathrm{J}$ Cancer 131:2632-2642

34. Kobayashi M, Hashimoto S, Nishikura K, Mizuno K, Takeuchi M, Sato Y, Ajioka Y, Aoyagi Y (2013) Magnifying narrow-band imaging of surface maturation in early differentiated-type gastric cancers after Helicobacter pylori eradication. J Gastroenterol 48:1332-1342

35. Yamamoto K, Kato M, Takahashi M, Haneda M, Shinada K, Nishida U, Yoshida T, Sonoda N, Ono S, Nakagawa M, Mori Y, Nakagawa S, Mabe K, Shimizu Y, Moriya J, Kubota K, Matsuno Y, Shimoda T, Watanabe H, Asaka M (2011) Clinicopathological analysis of early-stage gastric cancers detected after successful eradication of Helicobacter pylori. Helicobacter 16:210-216

36. Shichijo S, Hirata Y, Sakitani K, Yamamoto S, Serizawa T, Niikura R, Watabe H, Yoshida S, Yamada A, Yamaji Y, Ushiku T, Fukayama M, Koike K (2015) Distribution of intestinal metaplasia as a predictor of gastric cancer development. J Gastroenterol Hepatol 30:1260-1264 